\title{
DEVELOPMENT AND VALIDATION OF AN ANALYTICAL METHOD FOR CONDENSED TANNIN EXTRACTS OBTAINED FROM THE BARK OF FOUR TREE SPECIES USING HPLC
}

\author{
Faustino Ruiz-Aquino ${ }^{1}$, Rossy Feria-Reyes ${ }^{2}$, José Guadalupe Rutiaga-Quiñones ${ }^{3}$, \\ Wenceslao Santiago-García ${ }^{\mathbf{1}}$, Mario Ernesto Suárez-Mota ${ }^{\mathbf{1}}$, \\ Héctor Hugo Esquivel-Reyes 1 \\ 1 Universidad De La Sierra Juárez \\ MÉxico \\ 2 Universidad De Guanajuato \\ MÉxico \\ 3 Universidad Michoacana De San Nicolás De Hidalgo \\ MÉxico
}

(RECEIVEd June 2020)

\begin{abstract}
Herein, we evaluated the content of condensed tannins present in the bark of four tree species that are Quercus laurina Humb. \& Bonpl., Quercus crassifolia Humb. \& Bonpl., Arbutus xalapensis Kunth, and Prunus serotina Ehrn. An analytical method using high-performance liquid chromatography (HPLC) for condensed tannin extracts was developed and validated. Also, the aqueous extracts were analyzed by Fourier transform infrared spectroscopy (FTIR). Based on the Stiasny number, $A$. xalapensis, and $Q$. laurina represent an important source of condensed tannins, which may be subject to exploitation. Using infrared spectroscopy, it was observed that tannins do not show an important signal of carbonyl groups (aromatic esters) with respect to high purity catechin. Furthermore, the band of the hydroxyl group is less pronounced in tannins, because various hydroxyl are interacting with each other. However, it can be seen that the method of extraction of wood tannins developed in this work, presents satisfactory results.
\end{abstract}

KEYWORDS: Stiasny number, infrared spectroscopy, liquid chromatography.

\section{INTRODUCTION}

In the forests of the Sierra Juárez, Oaxaca, Mexico, stands with structural dominance of Quercus laurina Humb \& Bonpl., and Quercus crassifolia Humb. \& Bonpl. have been found, species that cohabit with Arbutus xalapensis Kunth, and Prunus serotina Ehrn, among 
others (Ruiz-Aquino et al. 2015). The wood of these species is used in rustic constructions (Ruiz-Aquino et al. 2016, 2019), and the elaboration of charcoal for fuel, and for its bark there are no reports on its use. The bark of the trees is considered a waste product, if the debarking is carried out in the industry it becomes a pollutant, while in the debarking in the field the bark is integrated as nutrients into the soil (Giménez et al. 2008). The bark is an important source of resins, latex, tannins, and substances that protect the tree from fungi and insects (Cuttler et al. 2007). In the bark of forest species of the families Clusiaceae, Cupressaceae, Ebenaceae, Fabaceae, Fagaceae, Sapotaceae, Pinaceae, among others, some authors have shown that condensed tannins are both chemically and economically interesting for the preparation of adhesives and resins destined to the production of particleboards and that they could be successfully used as substitutes for phenol in the production of phenol-formaldehyde resins (Tondi et al. 2010, Naima et al. 2015). Plant tannins or polyphenols are secondary metabolites distributed in sectors of the plant kingdom (Isaza 2007), can represent 2 to $40 \%$ of the dry bark mass of various forest species (Paes et al. 2006). They are chemically classified into hydrolyzable and condensed. Hydrolyzables are glucose polyesters, whereas condensates are made of catechin monomers and are known as flavonoids (Pizzi 1983).

Currently tannin compounds extraction is diverse, for example Bosso et al. (2016) analyzed the extracting effectiveness tannins grapes in some solvents (water, ethanol, acetone, ethyl acetate), used as pure or in binary and ternary mixtures. But, the polyphenolic compounds of tannins are molecules belonging to classes different from one another for the degree of polarity. The extraction method to be employed is influenced by the chemical nature of the substance, sample particle size, and also by the presence of interfering substances. Extraction time, temperature, solvent-to-feed ratio, the number of repeated extractions of the sample, as well as the choice of extraction solvents are the crucial parameters affecting the extraction yield. Solubility is influenced by both extraction time and temperature. A higher temperature simultaneously increases solubility and mass transfer velocities as well as decreases viscosity and surface tension of solvents contributing to a higher extraction rate (Mojzer et al. 2016).

This study evaluates the purity potential of tannin extraction in the bark of four tree species that are Q. laurina Humb. \& Bonpl., Q. crassifolia Humb. \& Bonpl., Arbutus xalapensis Kunth, and Prunus serotina Ehrn., and an analytical method is developed by HPLC, for the characterization of functional groups, Fourier transform infrared spectroscopy (FT-IR) is used.

\section{MATERIAL AND METHODS}

\section{Study area}

The study was conducted in the Ixtlán de Juárez forest, Oaxaca, Mexico, which is located $170^{\circ} 18^{\prime} 16^{\prime \prime}-170^{\circ} 34^{\prime} 00^{\prime \prime} \mathrm{N}$ and $96^{\circ} 31^{\prime} 38^{\prime \prime}-96^{\circ} 20^{\prime} 00^{\prime \prime} \mathrm{O}$, the climate is temperate humid and subhumid with rains in summer (Castellanos-Bolanos et al. 2008). The forest harvesting area is located at an altitude of 2,156 to $2,458 \mathrm{~m}$.

\section{Material collection}

Part of the bark of the standing trees was removed, trying not to damage the entire circumference of the stems to ensure the transport of nutrients and photoassimilates in the trees. The bark samples were oven dried at $103^{\circ} \mathrm{C}$ for 48 hours (Paes et al. 2006). Subsequently, they were crushed using a Wiley ${ }^{\circledR}$ mill and sieved with a mesh with an opening size of $1 \mathrm{~mm}$ (AguilarLópez et al. 2012). 


\section{Tannin extraction}

Tannin extraction was carried out with $5.0 \mathrm{~g}$ of ground bark and $75.0 \mathrm{~mL}$ of distilled water, $100 \mu \mathrm{l}$ of glacial acetic acid is added to the aqueous medium in a $250 \mathrm{~mL}$ Erlenmeyer flask, in a water bath at $87^{\circ} \mathrm{C}$. The addition of acetic acid is to prevent oxidation of tannin extracts. Subsequently, the cold extract was filtered using 11 micron porosity Whatman brand filter paper and the filtrate was adjusted to $100 \mathrm{~mL}$ (Pedraza-Bucio and Rutiaga-Quiñones 2011).

\section{Total extract}

For the quantification of condensed tannins, the remaining volume $(50 \mathrm{~mL})$ was used; $5.0 \mathrm{~mL}$ of formaldehyde and $2.5 \mathrm{~mL}$ of $\mathrm{HCl}$ were added to this solution using a Soxhlet system for $30 \mathrm{~min}$. It was subsequently filtered and the filtrate was dried at $105^{\circ} \mathrm{C}$ for 24 hours. The Stiasny number is calculated using equation Eq. 1 (Paes et al. 2006):

$$
N S=\frac{W_{1}}{W_{2}} \times 100
$$

where: NS = Stiasny number; $\mathrm{W} 1=$ solid mass $(\mathrm{g})$ in $100 \mathrm{~mL}$ of extract; $\mathrm{W} 2$ = precipitate mass $(\mathrm{g})$ in formaldehyde.

With the Stiasny number and the total extract amount, the amount of condensed tannins $T C=\frac{N S \times E T}{100}$

where: $\mathrm{TC}=$ condensed tannins (\%); NS = Stiasny number; ET = total extract (\%).

All extractions were performed in triplicate.

\section{Liquid chromatographic system}

All reagents used were HPLC grade, catechin HPLC grade, methanol, phosphoric acid (sigma Aldrich), Milli-Q water of $18.0 \mu \mathrm{S}$. The analysis was carried out in a CC5-BAS liquid chromatograph equipped with a quaternary pump, with an UV-116 BAS detector. Thermo Scientific Hypersil BDS $C_{18}$ reverse phase column of $250 \mathrm{~mm} \times 4.6 \mathrm{~mm}$ and $5.0 \mu \mathrm{m}$ particle size was used for this study. The peaks corresponding to catechin were detected at $\lambda=280 \mathrm{~nm}$ at elution time of $\mathrm{t}=2.57 \mathrm{~min}$ using a mobile phase methanol water $60: 40(\mathrm{v} / \mathrm{v} \%) \mathrm{nm}$, flow of $1.0 \mathrm{~mL} \cdot \mathrm{min}^{-1}$ in isocratic system.

\section{Analysis of tannin extracts by infrared spectroscopy with Fourier transforms}

For the identification of the functional groups present the tannin extracts a Spectrum 100 FT-IR Spectrometer was used in a wave number range between $500-4500 \mathrm{~cm}^{-1}$.

\section{Method development for identification of tannin}

For the analysis by liquid chromatography a standard of high purity catechin was used, the detection method was optimized to identify the tannins of the wood extracts. From a solution of $2000 \mathrm{mg} \cdot \mathrm{L}^{-1}$ of catechin HPLC grade dissolved in a $3.0 \mathrm{mM}$., solution of $\mathrm{H}_{3} \mathrm{PO}_{4}$. Solutions of 300.0, 250.0, 180.0, 130.0, 80.0, 40.0, 25.0, $10.0 \mathrm{mg} \cdot \mathrm{L}^{-1}$ were prepared and diluted with a $3.0 \mathrm{mM}$, solution of $\mathrm{H}_{3} \mathrm{PO}_{4}$. The addition of phosphoric acid in the samples is to prevent oxidation 
and to obtain a better chromatographic signal from the tannin. For this study a mobile phase of $\mathrm{MeOH} / \mathrm{H}_{2} \mathrm{O}(60: 40 \mathrm{v} / \mathrm{v} \%)$ was used at $\lambda=280 \mathrm{~nm}$, flow $1.0 \mathrm{ml} \cdot \mathrm{min}^{-1}$, the system flow was isocratic, 1980 psi pressure and $\approx 32^{\circ} \mathrm{C}, 20 \mu \mathrm{L}$ of the sample was injected into the chromatographic column, all samples were made in triplicate. Linear regression of each of the areas under the curve of the chromatograms checked the linearity of the same; the results represented the average of three curves performed.

\section{Linearity, precision, accuracy, detection and quantification limits}

The method linearity, recovery, precision (repeatability and intermediary precision), detection and quantification limits were evaluated according to Borman and Elder (2017). The linearity of the curves was estimated by regression using the last square method. The slope, intercept (with respective confidence intervals) and coefficient of determination $\left(\mathrm{R}^{2}\right)$ were calculated and evaluated. Each test catechin standard and tannin extractive solution of tree selective was injected in triplicate and the repeatability was evaluated for peak areas and retention times of tannin through the relative standard deviation (RSD) (\%).

\section{RESULTS AND DISCUSSION}

In Tab. 1 the average content of total extract, Stiasny number and condensed tannins of the four tree species under study is presented. The amount of total extract of $Q$. crassifolia y A. xalapensis is higher than that reported for the heartwood of Haematoxylon brasiletto Karst (7.6\%) (Pedraza-Bucio y Rutiaga-quiñones 2011), and also higher than the maximum reported for the bark of eight pine species from the Durango state Mexico (2.36 - 10.61\%) (Rosales and Gonzalez 2003). The differences found are attributed to two factors, the first is the extraction conditions and the second is the specific characteristics of each species, related to the chemical composition, site conditions and age of the tree species (Paes et al. 2006).

Tab. 1: Total extract, number of Stiasny, and condensed tannins in the bark of four tree species.

\begin{tabular}{|l|c|c|c|c|}
\hline \multirow{2}{*}{ Content } & \multicolumn{4}{|c}{ Bark of tree species (\%) } \\
\cline { 2 - 5 } & Prunus serotina & Quercus crassifolia & Arbutus xalapensis & Quercus laurina \\
\hline Total extract & $2.84(0.23)$ & $13.74(0.78)$ & $10.70(0.44)$ & $6.35(0.13)$ \\
\hline Stiasny number & $24.21(2.62)$ & $36.37(5.03)$ & $53.73(6.27)$ & $66.79(0.90)$ \\
\hline Condensed tannins & $0.68(0.02)$ & $4.97(0.41)$ & $5.73(0.43)$ & $4.24(0.14)$ \\
\hline
\end{tabular}

(RSD) (\%)- the values in parenthesis represent the standard deviation.

A higher percentage of Stiasny was found in the bark of Q. laurina (66.79\%), this value is slightly lower than that reported by Rosales and González (2003) for Pinus ayacabuite (69\%) and Pinus durangensis (69.3\%). Stiasny values greater than 65 represent an important source of condensed tannins (Rosales et al. 2002). The amount of condensed tannins is within the range $(0.41 \%-13.67 \%)$, reported for the bark of eleven wood species from Costa Rica (Aguilar-Lopez et al. 2012), the values are lower than those reported for the bark of four species of pine in Brazil (7.85\% - 13.82\%) (Da Silva et al. 2012). Condensed tannins have applications in formulating wood adhesives (Aguilar-López et al. 2012), in leather tanning (Colín-Urieta et al. 2013), the use of condensed tannins in ruminants has shown beneficial effects (Márquez and Suárez 2008) among others. High performance liquid chromatography 
was used to verify the purity of the tannins obtained with the extraction method implemented.

The optimized liquid chromatography conditions were achieved after preliminary assays, where different combination of methanol, water and a mixture phosphoric acid $3.0 \mathrm{mM}$ were tested, the results is show following.

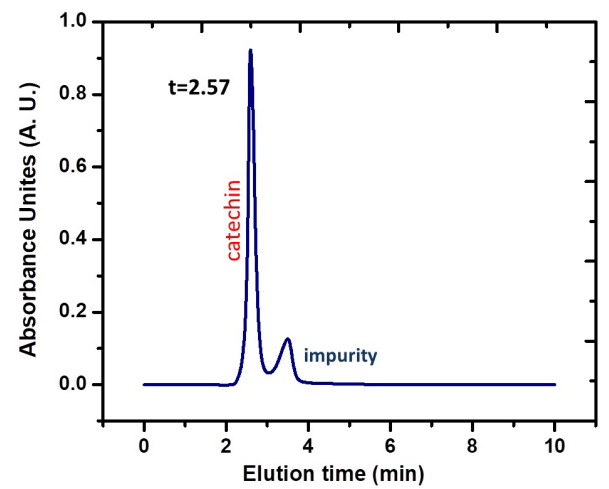

Fig.1:Chromatogram of $300 \mathrm{mg} \cdot \mathrm{L}^{-1}$ catechin standard with isocratic flow rate conditions $1.0 \mathrm{~mL}$. $\mathrm{min}^{-1}$, mobile phase of $\mathrm{MeOH} / \mathrm{H}_{2} \mathrm{O}(60: 40 \mathrm{v} / \mathrm{v} \%) \lambda=280 \mathrm{~nm}, 1980$ psi of pressure system and $\approx 32^{\circ} \mathrm{C}, 20 \mu \mathrm{L}$ sample injection and Thermo Scientific Hypersil BDS C18 reverse phase column of $250 \mathrm{~mm} \times 4.6 \mathrm{~mm}$ and $5.0 \mu \mathrm{m}$ particle size was using.

The Fig. 1 shows a chromatogram good defined of $300 \mathrm{mg} \cdot \mathrm{m}^{-1}$ catechin standard at elution time of $\mathrm{t}=2.54 \mathrm{~min}$, posteriorly at time $=3.5 \mathrm{~min}$ we observed a signal of impurity of standard, the flow of system was isocratic. Fig. 2 shows the chromatograms corresponding to calibration curves of 300 to $10 \mathrm{mg} \cdot \mathrm{m}^{-1}$ catechin standard, we can observe that a good linearity proportional at concentration analyzed. The linearity was evaluated for each standard substance. The calibration curves were obtained by plotting peak areas upon concentrations using eight standard solutions.

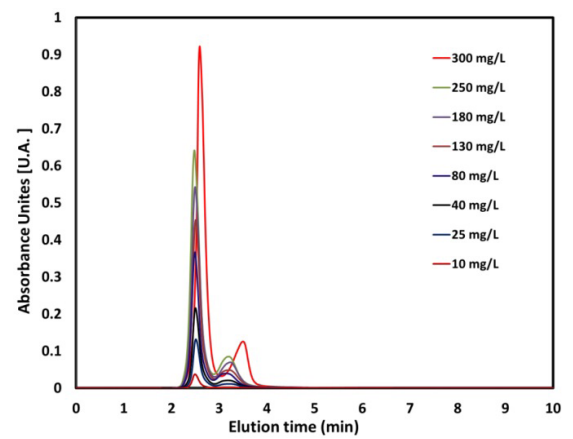

Fig. 2: Chromatograms of 300, 250, 180, 130,80, 40, 25, $10 \mathrm{mg} . \mathrm{L}-1$ catechin standard with isocratic flow rate conditions $1.0 \mathrm{~mL} . \mathrm{min}^{-1}$, mobile phase of $\mathrm{MeOH} / \mathrm{H} 2 \mathrm{O}(60: 40 \mathrm{v} / \mathrm{v} \%) \lambda=280 \mathrm{~nm}, 1980 \mathrm{psi}$ of pressure system and $\approx 32^{\circ} \mathrm{C}, 20 \mu \mathrm{L}$ sample injection and Thermo Scientific Hypersil BDS C18 reverse phase column of $250 \mathrm{~mm} \times 4.6 \mathrm{~mm}$ and $5.0 \mu \mathrm{m}$ particle size was using. 
The $\mathrm{R}^{2}$ values were greater than 0.997 , showing that the calculated regression curves could explain significantly the experimental variance (Fig.3) . Thus, the calculated straight line could explain more than $99 \%$ of the experimental data. The confidence intervals for both intercept points included zero.

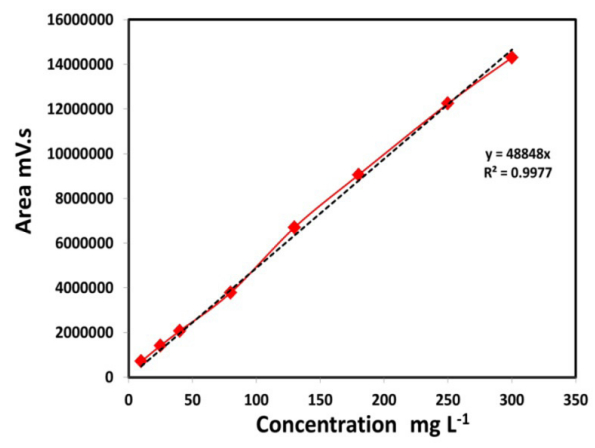

Fig. 3: Calibration curves of catechin standard.

Therefore, the result confirms the absence of constant systematic errors in the analytical method. The detection, and quantification limits were estimated from the calibration curve slopes. The limits of detection were $10 \mathrm{mg} \cdot \mathrm{L}^{-1}$ of catechin. With the standardized chromatographic method, the quantification of tannin extracts from the bark of the four wood species was carried out and analyzed.

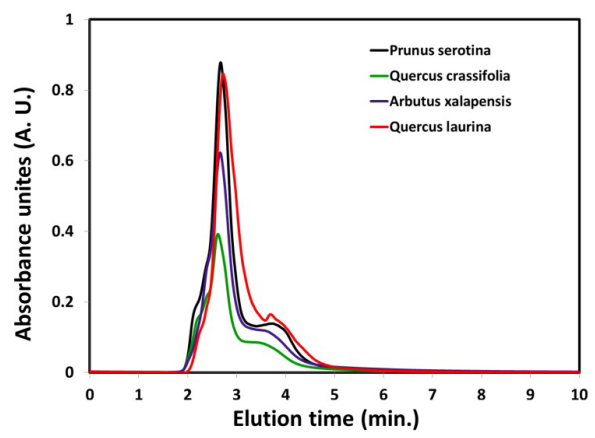

Fig. 4: Chromatograms of $40 \mathrm{mg} \cdot \mathrm{L}^{-1}$ of tannin extract from the bark of four tree species using isocratic flow rate conditions $1.0 \mathrm{~mL} \cdot \mathrm{min}^{-1}$, mobile phase of $\mathrm{MeOH} / \mathrm{H}_{2} \mathrm{O}(60: 40 \mathrm{v} / \mathrm{v} \%) \lambda=280 \mathrm{~nm}, 2280 \mathrm{psi}$ of pressure system, and $\approx 32^{\circ} \mathrm{C}, 20 \mu \mathrm{L}$ sample injection and Thermo Scientific Hypersil BDS C18 reverse phase column of $250 \mathrm{~mm} \times 4.6 \mathrm{~mm}$, and $5.0 \mu \mathrm{m}$ particle size was using.

Fig. 4 shows the chromatograms corresponding to the tannin extracts from the bark of the four species under study obtained with the extraction method implemented. The signal shows that the elution times of the extracted tannins are, the elution time of the tannin is $\mathrm{t}=2.78 \mathrm{~min}$, and it is observed that at $\mathrm{t}=3.2 \mathrm{~min}$ is the signal corresponding to the impurity of the tannin extracted is observed for each of the barks of the species under study. This shift in the retention time of the tannin is due to the presence of carboxylic groups present in the wood 
tannin extract that exert a greater pressure on the chromatographic column, and this causes the slight displacement of the sample with respect to when you have the high purity standard.

Thus, the amount of total tannins obtained for each of the bark species are: Prunus serotina $290 \mathrm{mg} \mathrm{L}^{-1}$, Quercus crassifolia $130 \mathrm{mg} \mathrm{L}^{-1}$, Arbutus xalapensi $250 \mathrm{mg} \mathrm{L}^{-1}$, and Quercus laurina $275 \mathrm{mg} \mathrm{L}^{-1}$. In the extraction of tannins it is important the polarity of solvent depends on its dielectric constant $(\varepsilon)$, which affects the capacity of the solvent to solubilize molecules tannin compounds with different degree of polarity. Where the water dielectric constant is $\varepsilon=80.1$, and $\varepsilon=6.2$ acid acetic (Naima et al. 2015). In this work, the use of acetic acid acts as a protic solvent in the extraction medium with water. The acid present in the extraction process prevents the oxidation of tannins in an aqueous medium, which is reflected in the chromatographic analysis.

The tannins present in the wood extracts are condensable, of which there are three structured groups of tannins that are; hydrolyzed tannins, condensable tannins, and phlorotannins, which are produced through three different biosynthetic pathways. Hydrolyzable tannins are produced by a shikimic acid pathway that leads to the production of gallic acid (the fundamental monomer unit). Phlorotannines are derived from the Malonyl-CoA pathway produced by the phloroglucinol building block while condensed tannins are derived by mixed biosynthesis from the above two pathways that produce Flavan-3,4-diol (monomer units) which are then polymerized by condensation (Stafford 1983).

\section{Spectroscopy FTIR}

Fig. 5 shows the infrared spectrum that corresponds to the catechin standard and that is used to compare with the tannin extracts under study. In the spectrum it is observed that the main signals correspond to slight displacements according to what was reported by Silverstein and Bassler (1962), which is probably related to the presence of different types of phenols.

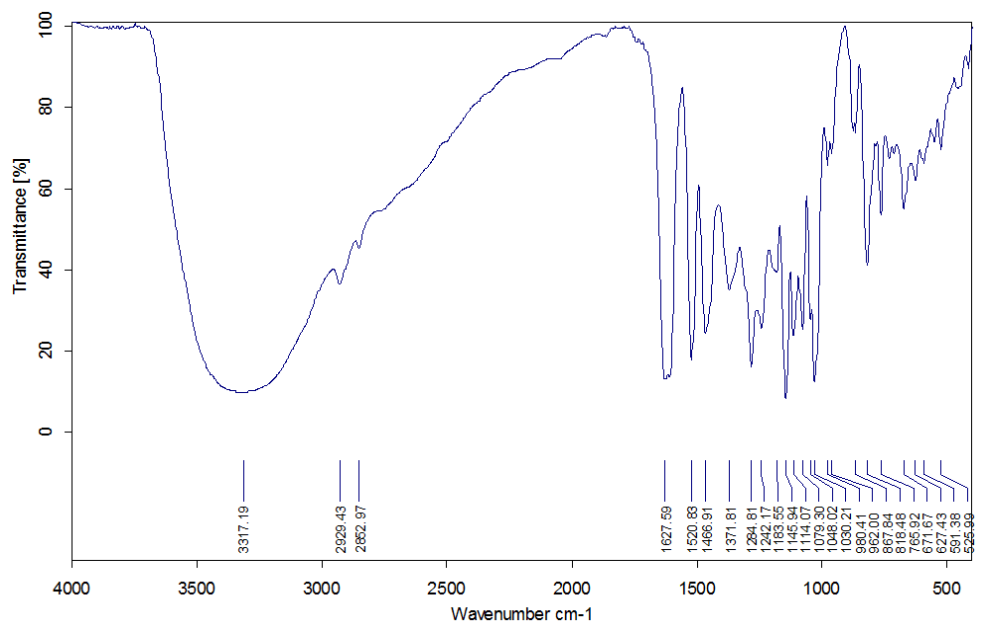

Fig. 5: Infrared spectroscopy of catechin standard.

The spectrum of catechin where it can find a strong absorption around 3600, and $3000 \mathrm{~cm}^{-1}$ with a wide and strong band centered at $3317.9 \mathrm{~cm}^{-1}$ respectively. These bands are assigned to the hydroxyl groups $(\mathrm{OH})$ stretching vibrations and due to the wide variety of hydrogen bonding 
between $\mathrm{OH}$. In this spectrum it can notice a sharp peak at $2929.43 \mathrm{~cm}^{-1}$ associated with the symmetric and antysimmetric -C-H- stretching vibrations of $\mathrm{CH}_{2}$ and $\mathrm{CH}_{3}$ groups respectively. Also it does not appear signals of free water molecules due there is no evidence of bands at $2150 \mathrm{~cm}^{-1}$ and $1650 \mathrm{~cm}^{-1}$ (H-O-H bending vibrations), and at about $700 \mathrm{~cm}^{-1}$. The deformation vibration of the carbon-carbon bonds in the phenolic groups absorbs in the region of $1600-1475 \mathrm{~cm}^{-1}$. At $750 \mathrm{~cm}^{-1}$ shows the result distortion vibration of $\mathrm{C}=\mathrm{C}$ in benzene rings. Around $1460 \mathrm{~cm}^{-1}$ stretching vibrations of $-\mathrm{C}-\mathrm{C}_{\text {aromatic }}$ groups appear (Socrates 2001). Tab. 2 shows details of the peaks found by FTIR of the catechin standard.

Tab. 2: Main FTIR signals of the catechin standard and its comparison with those of the literature (Socrates 2001).

\begin{tabular}{|c|c|c|c|}
\hline $\begin{array}{l}\text { Frequency }\left(\mathrm{cm}^{-1}\right) \\
\text { (Catechin stand.) }\end{array}$ & Signal type & Chemical bond type & Assignment \\
\hline 3317.19 & Elongation & $\mathrm{O}-\mathrm{H}$ y N-H & Hydroxyls and amines \\
\hline 2929.43 & Asymmetric elongation & $\mathrm{C}-\mathrm{H}$ & $\mathrm{CH}_{2}$ saturation groups \\
\hline 2852.97 & Asymmetric elongation & $\mathrm{C}-\mathrm{H}$ & Hydrocarbons \\
\hline 1627.59 & $\begin{array}{l}\text { Symmetrical bending } \\
\text { vibration }\end{array}$ & $\mathrm{C}=\mathrm{O}$ & $\begin{array}{l}\text { Flavonoid, lipids and amino } \\
\text { acids }\end{array}$ \\
\hline 1520.83 & Elongation & Aromatic compounds & $\begin{array}{l}\text { Flavonoids and aromatic } \\
\text { rings }\end{array}$ \\
\hline 1371.81 & Bending vibration & $\mathrm{C}-\mathrm{H}$ & Flavonoid group $\mathrm{CH}_{3}$ \\
\hline 1284.81 & $\begin{array}{l}\text { Bending vibration }(\mathrm{O}-\mathrm{H}) \\
\text { and asymmetric flexion } \\
(\mathrm{C}-\mathrm{CO})\end{array}$ & $\mathrm{O}-\mathrm{H}$ and $\mathrm{C}-\mathrm{CO}$ & Hydrocarbons \\
\hline 1242.17 & $\begin{array}{l}\text { bending vibration }(\mathrm{O}-\mathrm{H}) \\
\text { and asymmetric flexion } \\
(\mathrm{C}-\mathrm{CO})\end{array}$ & $\mathrm{C}-\mathrm{H}$ & Flavonoid group $\mathrm{CH}_{3}$ \\
\hline $\begin{array}{l}1183.55- \\
1079.30\end{array}$ & $\begin{array}{l}\text { Elongation vibration }(\mathrm{C}-\mathrm{C}) \\
\text { and flexion }(\mathrm{C}-\mathrm{OH})\end{array}$ & $\mathrm{C}-\mathrm{C}$ and $\mathrm{C}-\mathrm{OH}$ & $\begin{array}{l}\text { Flavonoids and secondary } \\
\text { alcohol groups }\end{array}$ \\
\hline 1048.02 & $\begin{array}{l}\text { Elongation }(=\mathrm{C}-\mathrm{O}-\mathrm{C}) \text {, } \\
\text { Elongation }(\mathrm{C}-\mathrm{C}) \text { and } \\
\text { flexion }(\mathrm{C}-\mathrm{OH})\end{array}$ & $=\mathrm{C}-\mathrm{O}-\mathrm{C}, \mathrm{C}-\mathrm{C}$ and $\mathrm{C}-\mathrm{OH}$ & Primary alcohols group \\
\hline 1030.21 & $\begin{array}{l}\text { Elongation vibration }(\mathrm{C}-\mathrm{C}) \\
\text { and flexion }(\mathrm{C}-\mathrm{OH})\end{array}$ & $\mathrm{C}-\mathrm{C}$ and $\mathrm{C}-\mathrm{OH}$ & $\begin{array}{l}\text { Flavonoids and second. } \\
\text { alcohol groups }\end{array}$ \\
\hline 867.84 & $\begin{array}{l}\text { Symmetric stretching } \\
\text { vibration }\end{array}$ & $\mathrm{C}-\mathrm{C}-\mathrm{O}$ & $\begin{array}{l}\text { Primary and } \\
\text { secondary alcohols }\end{array}$ \\
\hline $818.48-525.94$ & $\begin{array}{l}\text { Symmetric stretching } \\
\text { vibration }(\mathrm{C}-\mathrm{H})\end{array}$ & Aromatic compounds & $\begin{array}{l}\text { Primary and secondary } \\
\text { alcohols outside the flexion } \\
\text { plane }\end{array}$ \\
\hline
\end{tabular}

Fig. 6 shows the infrared spectra of tannins extracted with water from the bark of the four timber species. An in-depth analysis by infrared micro spectroscopy indicates that the main tannin-related bands are found in 1727,1612 , and $1513 \mathrm{~cm}^{-1}$, in these wave number ranges: (i) Region carbonyl region 1800-1480 $\mathrm{cm}^{-1}$; including: carbonyl groups (ester, ketone, aldehyde, amide I), amide II, carboxylate groups and aromatic groups, (ii) Region carbohydrate region $1190-850 \mathrm{~cm}^{-1}$; including all bands of carbohydrates n (C-O-C) (Silverstein and Bassler 1962). 
The spectra obtained here are found in the region $650-4000 \mathrm{~cm}^{-1}$, recorded by L. Chupin et al. (2013), for the bark of Pinus pinaster extracted with different conditions, where the band at $3300 \mathrm{~cm}^{-1}$ is assigned as $\mathrm{OH}$ stretch vibration in phenolic and aliphatic structures, in the same way, Jablonski et al. (2015), assigned to the hydroxyl group stretching vibration a broad band at $\sim 3300 \mathrm{~cm}^{-1}$.

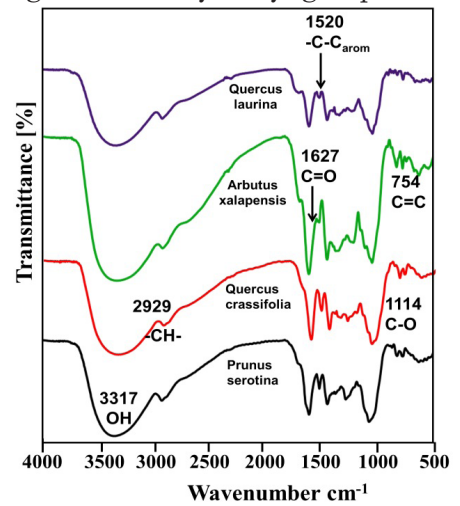

Fig. 6: Infrared spectroscopy of the four types of bark.

Detailed information is listed in Tab. 3; these results are similar to those reported in the literature for polyphenolic compounds as tannins, and tannic acid (Hillis 1964).

Tab. 3: Wave range limits and corresponding absorption bands for standardized integration method applied to all FPA and synchrotron IR maps.

\begin{tabular}{|l|l|}
\hline Integration region No. & \\
\hline I) $1705-1570 \mathrm{~cm}^{-1}$ & $v(\mathrm{C}=\mathrm{O})$; amide \\
\hline & $v_{\mathrm{as}}(\mathrm{COO}-)$; \\
\hline & $v(\mathrm{C}=\mathrm{C})$; aromatic quadrant ring stretch \\
\hline II) $1530-1480 \mathrm{~cm}^{-1}$ & $v(\mathrm{C}=\mathrm{C})$; aromatic semicircle ring stretch \\
\hline III) $1260-1210 \mathrm{~cm}^{-1}$ & $v(\mathrm{C}-\mathrm{C}), v(\mathrm{C}-\mathrm{O})$ (lignin) \\
\hline Iv) $1180-950 \mathrm{~cm}^{-1}$ & $v(\mathrm{C}-\mathrm{O}-\mathrm{C})$ (carbohydrates) \\
\hline
\end{tabular}

\section{CONCLUSIONS}

Of the tree barks evaluated in this work and based on the Stiasny number, the Arbutus xalapensis and Quercus laurina species contain a significant amount of condensed tannins of $10.7 \%$ and $6.3 \%$, respectively which can be exploited. Using infrared spectroscopy, it was observed that the tannins do not show an important signal of the carbonyl groups (aromatic esters) with respect to the high purity catechin. The band of the hydroxyl group in tannins is less pronounced, because several hydroxyls are bonded. With the extraction method used and the analytical method developed for the quantification of tannins from the bark of trees, they show that the tannins of the tree species Prunus serotina and Quercus crassifolia are around $83 \%$ approximately and these extracts show a high purity with respect to the Catequina standard.

These results compared with the different extraction methods for tannins show a similar performance in terms of extraction yields and amount of tannins extracted; the use of solvents is low and economically feasible for future work. 


\section{REFERENCES}

1. Aguilar-López, J., Jaén-Jiménez, J.C., Vargas-Abarca, A.S., Jiménez-Bonilla, P., Vega-Guzmán, I., Herrera-Núñez, J., Borbón-Alpízar, H., Soto-Fallas, R.M., 2012: Extraction and evaluation of condensed tannins from the bark of eleven timber species from Costa Rica. Revista Tecnología en Marcha 25(4): 15-22.

2. Beltrán-Rodriguez, L., Maldonado-Almanza, B., Blancas, J., Sierra-Huelz, A., Cristians, S., Bye, R., 2018: Barks as non-timber forest products in Mexico: national analysis and recommendations for their sustainable use. CONACyT, México, $52 \mathrm{p}$.

3. Borman, P., Elder, D., 2017: Q2(R1) validation of analytical procedures. In: ICH Quality Guidelines: An Implementation Guide (ed. Teasdale A., Elder D., Nims RW). Pp 127-166, John Wiley \& Sons. USA.

4. Bosso, A., Guaita M., Petrozziello, M., 2016: Influence of solvents on the composition of condensed tannins in grape pomace seed extracts. Food Chemistry 207: 162-169.

5. Castellanos-Bolaños, J.F., Treviño-Garza, E.J., Aguirre-Calderón, O.A., Jiménez-Pérez, J., Musalem-Santiago, M., López-Aguillón, R., 2008: Forest structure of managed Patula pine in Ixtlán de Juárez, Oaxaca, Mexico. Madera y Bosques 14(2): 51-63.

6. Colín-Urieta, S., Ochoa-Ruiz, H.G., Rutiaga-Quiñones, J.G., 2013: Tannin content in the bark of two species of paracata (Erythroxylon compactum Rose and Senna skinneri Benth. Irwin \& Barneby). Revista Chapingo serie ciencias forestales y del ambiente 19(1): 115-124.

7. Cutler, D., Botha, T., Stevenson, D., 2007: Plant anatomy: An applied approach. WileyBlackwell. England, 312 p.

8. Da Silva, F.E., Costa, L.R.C.,Oliveira, B.E., Nascimento, A.M., Da Silva, M.L., 2012: Tannin contents in the bark of four pinus species. Floresta e Ambiente 16(2): 30-39.

9. Gimenez, A.M., Moglia, J.G., Hernandez, P., Gerez, R., 2008: The feasibility of increasing the Chaco forests value by exploiting the forest bark. Quebracho-Revista de Ciencias Forestales (15): 9-14.

10. Hillis, W., 1964: The formation of polyphenols in trees. 2. The polyphenols of Eucalyptus sieberiana Kino. Biochemical Journal 92: 516-521.

11. Isaza, J.H., 2007: Vegetable tannins or polyphenols. Scientia et technica 1(33): 13-18.

12. Jablonsky, M., Vernarecová, M., Ház, A., Dubinyová, L., Skulcova, A., Sladková, A., Surina, I., 2015: Extraction of phenolic and lipophilic compounds from spruce (Picea abies) bark using accelerated solvent extraction by ethanol. Wood Research 60(4): 583-590.

13. L, Chupin, Motillon, C., Charrier-El Bouhtoury, F., Pizzi, A., Charrier, B., 2013: Characterisation of maritime pine (Pinus pinaster) bark tannins extracted under different conditions by spectroscopic methods, FTIR and HPLC. Industrial Crops and Products 49: 897-903.

14. Marquez Lara, D., Suarez Londoño, Á., 2008: The use of condensed tannins as a nutritional and sanitary alternative in ruminants. Revista de Medicina Veterinaria 1(16): 87-109.

15. Mojzer, E., Hrnčič, M., Škerget, M., Knez, Ž., Bren, U., 2016: Polyphenols: Extraction methods, antioxidative action, bioavailability and anticarcinogenic effects. Molecules 21(7): 1-38.

16. Naima, R., Oumam, M., Hannache, H., Sesbou, A., Charrier, B., Pizzi, A., CharrierE1 Bouhtoury, F., 2015: Comparison of the impact of different extraction methods on polyphenols yields and tannins extracted from Moroccan Acacia mollissima barks. Industrial Crops and Products 70: 245-252.

17. Paes, J.B., Diniz, C.E.F., Marinho, I.V., de Lima, C.R., 2006: Tannin potencial evaluation of six forest species of Brazilian semi-arid region. Cerne 12(3): 232-238. 
18. Pedraza-Bucio, F.E., Rutiaga-Quiñones, J.G., 2011: Tannic extract of Brazilian Palo wood. Revista Conciencia Tecnológica 42: 36-41.

19. Pizzi, A., 1983: Tanin-based adhesives. In: Wood adhesives: chemistry and technology. (ed. M. Dekker). Pp 177-246, New York.

20. Rosales, C.M., Gonzales, L.R.F., 2003: Comparison of the content of phenolic compound in the bark of eight pine species. Madera y Bosques 9(2): 41-49.

21. Rosales, M., Galindo, A., González, R.F., 2002: Tannins condensed in the bark of Pinus chibuahuana and Pinus durangensis. Información Tecnológica 13(1): 39-42.

22. Ruiz-Aquino, F., González-Peña, M.M., Valdez-Hernández, J.I., Romero-Manzanares, A., 2016: Anatomical structure of the wood of two oaks from Oaxaca. Madera y bosques 22(1): 177-189.

23. Ruiz-Aquino, F., Ruiz-Ángel, S., Santiago-García, W., Fuente-Carrasco, M.E., SotomayorCastellanos, J.R., Morelia, M., Carrillo-Parra, M.A., 2019: Energy characteristics of wood and charcoal of selected tree species in Mexico. Wood Research 64(1): 71-82.

24. Ruiz-Aquino, F., Valdez-Hernández, J.I., Romero-Manzanares, A., Manzano-Méndez, F., Fuentes-López, M.E., 2015: Spatial distribution of two oak species and ecological attributes of pine-oak woodlands from Ixtlán de Juárez, Oaxaca. Revista Chapingo. Serie Ciencias Forestales y del Ambiente 21(1): 67-80.

25. Silverstein, R.M., Bassler, G.C., 1962: Spectrometric identification of organic compounds. Journal of Chemical Education 39(11): 546-553

26. Socrates, G., 2001: Infrared and Raman characteristics group frequencies, tables and chart. 3a. ed., John Wiley \& Sons, Inc., USA, 118 p.

27. Stafford, H.A., 1983: Enzymic regulation of procyanidin biosynthesis; lack of a flav-3-en3-ol intermediate. Phytochemistry 22(12): 2643-2646.

28. Tondi, G., Pizzi, A., Delmotte, L., Parmentier, J., Gadiou, R., 2010. Chemical activation of tannin-furanic carbon foams. Industrial Crops and Products 31 (2): 327-334.

Faustino Ruiz-Aquino*, Wenceslao Santiago-García, Mario Ernesto Suárez-Mota, Héctor Hugo Esquivel-Reyes

Universidad De La Sierra Juárez

Institute of Environmental Studies

Avenida Universidad S/N

68725, Ixtlán De JuÁrez

OAXACA

MÉXICO

*Corresponding author: ruiz.aquino@unsij.edu.mx

\author{
Rossy Feria-Reyes \\ Universidad De Guanajuato \\ Chemistry Department \\ Division of Natural And Exact Sciences \\ Cerro De la Venada S/N, Pueblito De Rocha \\ 36040, Guanajuato \\ MÉXICO
}


José Guadalupe
Rutiaga-Quiñones,

Universidad Michoacana De San Nicolás De Hidalgo

Faculty of Wood Technology Engineering

AV. FCO. J. Mújica, S/N, Colonia Felícitas Del Río

58040, Morelia, Michoacán

MÉxico 